\title{
SARS-CoV-2-associated acute disseminated encephalomyelitis: a systematic review of the literature
}

\author{
Yumin Wang ${ }^{1} \cdot$ Yanchao Wang $^{2} \cdot$ Liang Huo $^{3} \cdot$ Qiang Li $^{2} \cdot$ Jichao Chen $^{1} \cdot$ Hongquan Wang ${ }^{4}(\mathbb{D}$
}

Received: 10 August 2021 / Revised: 22 August 2021 / Accepted: 23 August 2021 / Published online: 30 August 2021

(c) Springer-Verlag GmbH Germany, part of Springer Nature 2021

\begin{abstract}
The literature on cases of acute disseminated encephalomyelitis (ADEM) associated with SARS-CoV-2 infection has been rapidly increasing. However, the specific clinical features of ADEM associated with SARS-CoV-2 (SARS-CoV-2-ADEM) have not been previously evaluated. We screened all articles resulting from a search of PubMed and Web of Science databases looking for reports of ADEM published between December 01, 2019, and June 5, 2021. Of the 48 ADEM cases identified from 37 studies, 34 (71\%) had ADEM while 14 (29\%) were of AHLE. RT-PCR for SARS-CoV-2 was positive in $83 \%(n=19)$ of patients. 26 patients $(54 \%)$ were male, and 18 patients (38\%) were female, with a male to female sex ratio of 1.4:1; median age was $44(1.4-71)$ years. 9 patients $(19 \%, 9 / 48)$ were children. Of the 9 children patients, their median age was 9 years (range 1.4-13 years), 6 patients (67\%) were female, and 2 patients (22\%) were male, with a female to male sex ratio of 3:1.39 patients (81\%) was performed CSF analysis. PCR for SARS-CoV-2 tested positive in 3 patients $(14 \%, 3 / 22)$ on CSF sample. 31 (64\%) of patients had a poor outcome on discharge from hospital. Five (10\%) patients died in hospital. Compared to classic ADEM, SARS-CoV-2-ADEM have a more longer duration between the onset of the antecedent infective symptoms and the start of ADEM symptoms, the older age distribution of the patients, relatively poor outcome, a lower full recovery rate, a more frequently brain lesions involved the periventricular white matter and corpus callosum, and less frequently affected the deep gray matter. Taken together, the present comprehensive review reveals that although rare, ADEM can be associated with SARS-CoV-2 infection. SARS-CoV-2-ADEM seems to share most features of classic ADEM, with moderate discrepancies from the classical ADEM.
\end{abstract}

Keywords COVID-19 · SARS-CoV-2 · Acute disseminated encephalomyelitis · Clinical features

Yumin Wang and Yanchao Wang contributed equally to this work.

Hongquan Wang

whognquan@alu.fudan.edu.cn

1 Department of Respiratory and Critical Care Medicine, Aerospace Center Hospital, Peking University

Aerospace School of Clinical Medicine, Beijing 100049,

People's Republic of China

2 Department of Neurology, The Affiliated Hospital of Chifeng University, Chifeng 024005, People's Republic of China

3 Department of Pediatrics, Shengjing Hospital of China Medical University, Shenyang 110004, China

4 Department of Neurology, Aerospace Center Hospital, Peking University Aerospace School of Clinical Medicine, Beijing 100049, People's Republic of China

\section{Introduction}

Coronavirus disease 2019 (COVID-19), which is caused by severe acute respiratory syndrome coronavirus 2 (SARSCoV-2), has rapidly evolved into a worldwide pandemic. COVID-19 predominantly affects the respiratory system and patients typically present with a cough, sore throat, fever, fatigue and breathing difficulties [1]. However, since Mao for the first time reported there is evidence of neurological involvement in COVID-19 [2], neurologic complications are increasingly recognized in the coronavirus disease 2019 (COVID-19) pandemic [3-6]. In detail, several pieces of evidence suggested potential neurologic complications of SARS-CoV-2 infection include anosmia, ageusia, anorexia, myalgias, headache, dizziness, meningoencephalitis, altered consciousness, Guillain-Barré syndrome, syncope, seizure, and stroke $[7,8]$. 
As a rare illness, acute disseminated encephalomyelitis (ADEM) is an inflammatory demyelinating disorder of the central nervous system (CNS) that predominantly affects children [9]. However, several studies reported an increased incidence of ADEM after SARS-CoV-2 epidemics around the world. More recently, numerous case report/series have described cases of ADEM linked to SARSCoV-2 infection, which suggests a possible association between ADEM and SARS-CoV-2 infection [10-15].

Until now, no systematic review has conducted to review the available information on the reports of ADEM associated with the COVID-19 infection. This study aims to perform a systematic review of all published studies on SARS-CoV2-related ADEM and give a comprehensive overview of the demographic characteristics, clinical features, diagnostic investigations, and outcome of SARS-CoV-2-related ADEM patients. At the same time, we also compare the clinical features of SARS-CoV-2-associated ADEM to the classical form of ADEM. The current study may get a better understanding of the acute and post-infectious manifestations of SARS-CoV-2-associated ADEM to guide long-term management and health service reorganization.

\section{Methods}

This systematic review was conducted according to the Preferred Reporting Items for Systematic Review and MetaAnalyses (PRISMA) guidelines [16, 17]. A PRISMA-P checklist has been provided as an online supplementary file. We conducted a thorough literature review in June 2021 using keywords (including all commonly used abbreviations of these terms) used in the search strategy were as follows: ("acute demyelinating encephalomyelitis;" OR "acute haemorrhagic leukoencephalitis") AND ("COVID-19"OR "SARS-CoV-2"). We searched PubMed and Web of Science databases for identifying case series and case reports published between December 1, 2019, to June 5, 2020. Suitable references were also identified in the authors' archives of scientific literature on ADEM. At least two independent reviewers independently screened all publications, including title and abstract, to determine whether studies include cases. Further case reports and case series studies were obtained by reference tracing of retrieved articles. We restricted our search to studies published in English. Publications that were not peer-reviewed were excluded from this study. For each case, we extracted data concerning demographic and clinical variables, results of diagnostic investigations, and outcome. Searches were performed by SAR, AA, and MF. The selection of relevant articles was shared with all authors.

According to our search criteria, we found 246 studies from PubMed and Web of Science. Duplicate studies, studies with missing clinical data, review articles and articles unrelated to our study objective were excluded and 31 fulltext literatures were reviewed in accordance with our study objective.

\section{Results}

A total of 48 patients with COVID-19 diagnosed with ADEM/AHLE were used for analyses from the 37 case reports and case series published between December 1, 2019 , to June 5, 2020. The demographic data, the clinical, laboratory and imaging findings of the 48 patients are detailed in Table 1 and summarised in Tables 2 and 3.

\section{Epidemiological distribution and demographic characteristics of the patients}

Of the 48 ADEM cases identified from 37 studies, 26 patients (54\%) were male and 18 patients $(38 \%)$ were female, with a male to female sex ratio of 1.4:1; median age was $44(1.4-71)$ years. 9 patients $(20 \%, 9 / 45)$ were children. Of the 9 children patients, their median age was 8 years (age range $1.4-13$ years), 6 patients $(75 \%, 6 / 8)$ were female, and 2 patients $(25 \%, 2 / 8)$ were male, with a female to male sex ratio of 3:1. Adult to children ratio is $4: 1(36 / 9)$, indicating that SARS-CoV-2-related ADEM predominantly affects adults after than children.

Overall, patients were reported from 10 countries but mostly from Europe $(43.7 \%, 21 / 48)$ and especially from UK (25.0\%). In details, patients were originally from USA $(n=13)$, United Kingdom $(n=12)$, Italy $(n=5)$, Brazil $(n=4)$, India $(n=3)$, Iran $(n=3)$, Singapore $(n=3)$, France $(n=3)$, Canada $(n=1)$, and Greece $(n=1)$ (Table 2$)$.

\section{Clinical features of SARS-CoV-2-associated ADEM}

Most common manifestations of COVID-19 included fever $(66.0 \%, 23 / 35)$, cough $(27.0 \%, 13 / 35)$, dyspnoea $(24.0 \%, 11 / 35)$, anosmia/hyposmia $(14.0 \%, 5 / 35)(17.0 \%$, $6 / 35)$, myalgia $(14.0 \%, 5 / 35)$, fatigue $(11.0 \%, 4 / 35)$, leth$\operatorname{argy}(9.0 \%, 3 / 35)$ and $\operatorname{rash}(6.0 \%, 2 / 35)$. Six patient [18-23] did not present any sign related to COVID-19. The diagnosis of SARS-CoV-2 infection was made by positive RT-PCR of nasopharyngeal swab in 18 (78\%) patients (sometimes after repeated tests) and when negative by in $5(21 \%)$ patient. SARS-CoV-2 RT-PCR with sputum exam was positive in 1 (3\%) patients, and when positive by serology in $3(10 \%)$ patient.

$34(71.0 \%)$ had ADEM while $14(29.0 \%)$ were of AHLE. In all $(n=48)$ but one patients [14], ADEM manifestations developed after those of COVID-19. Differently, the temporal relationship between onset of COVID-19 symptoms and ADEM was not reported or not calculable 


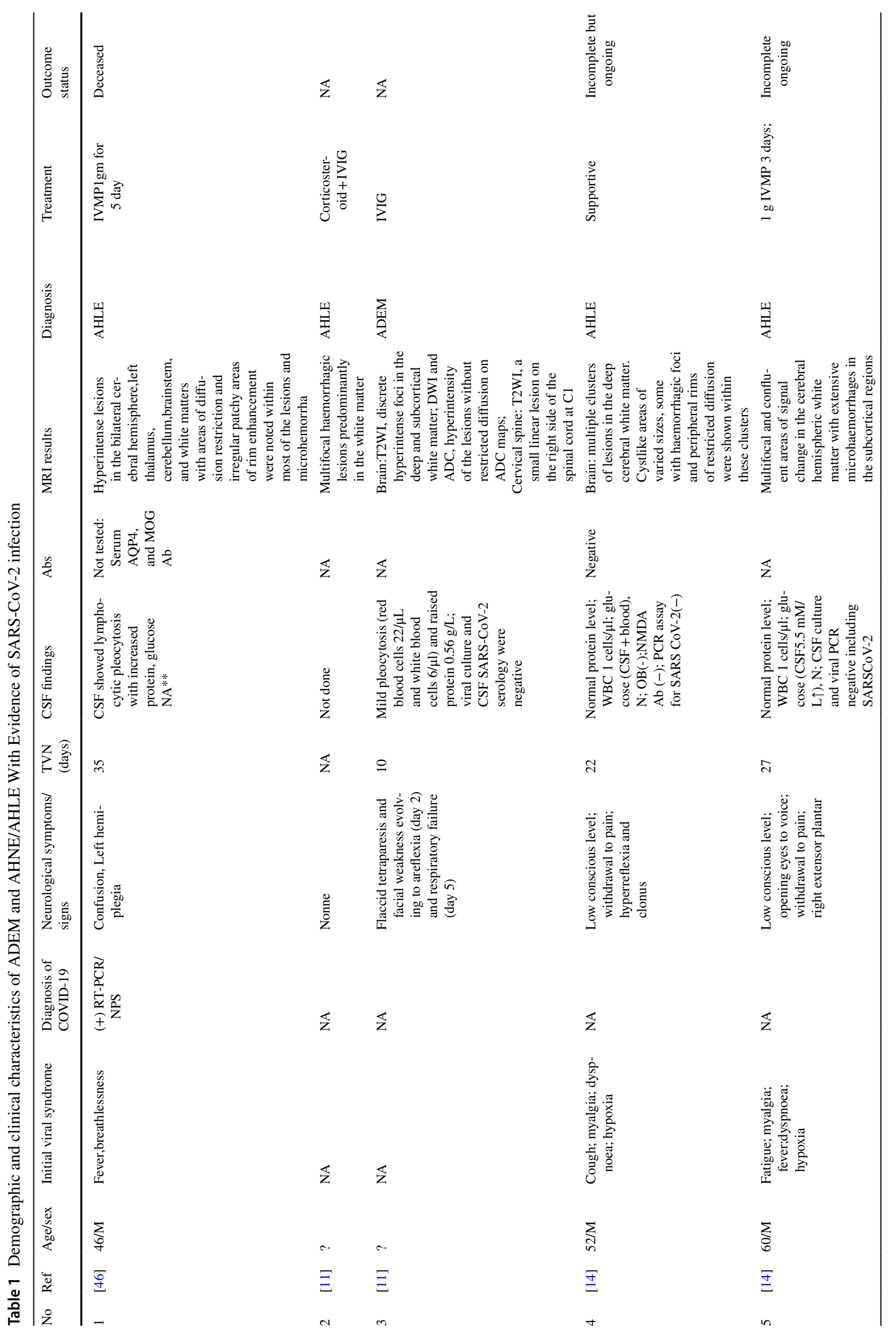




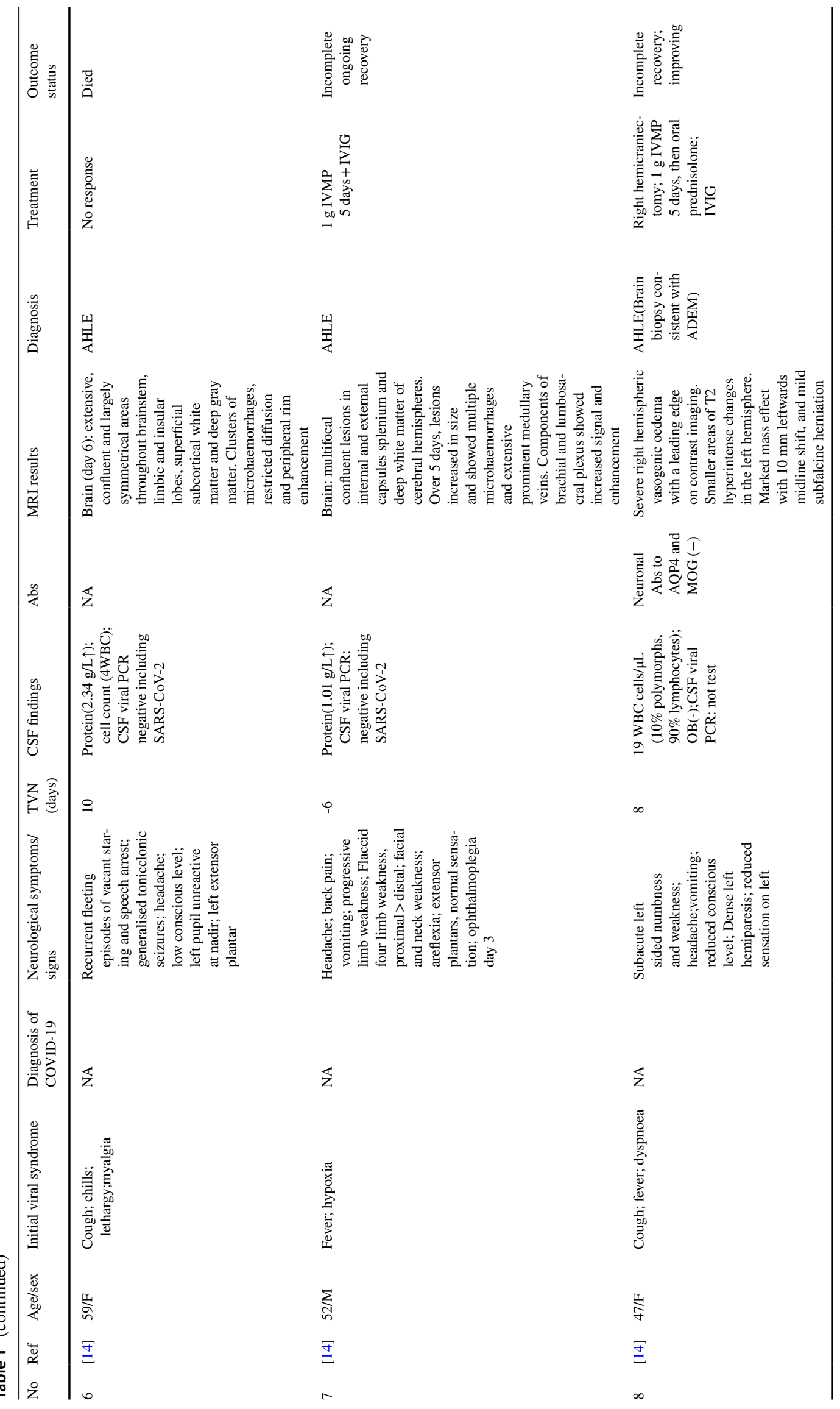




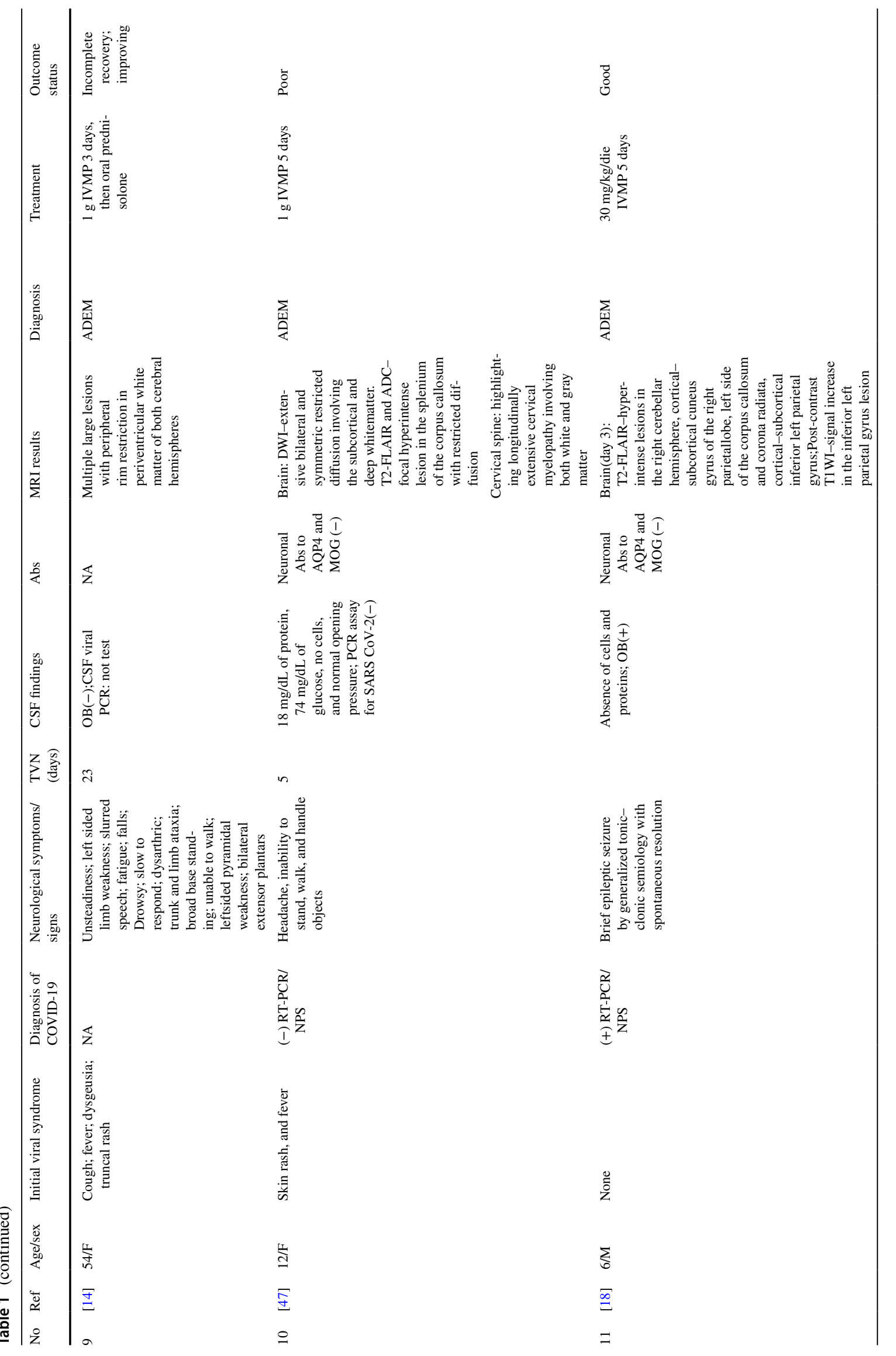




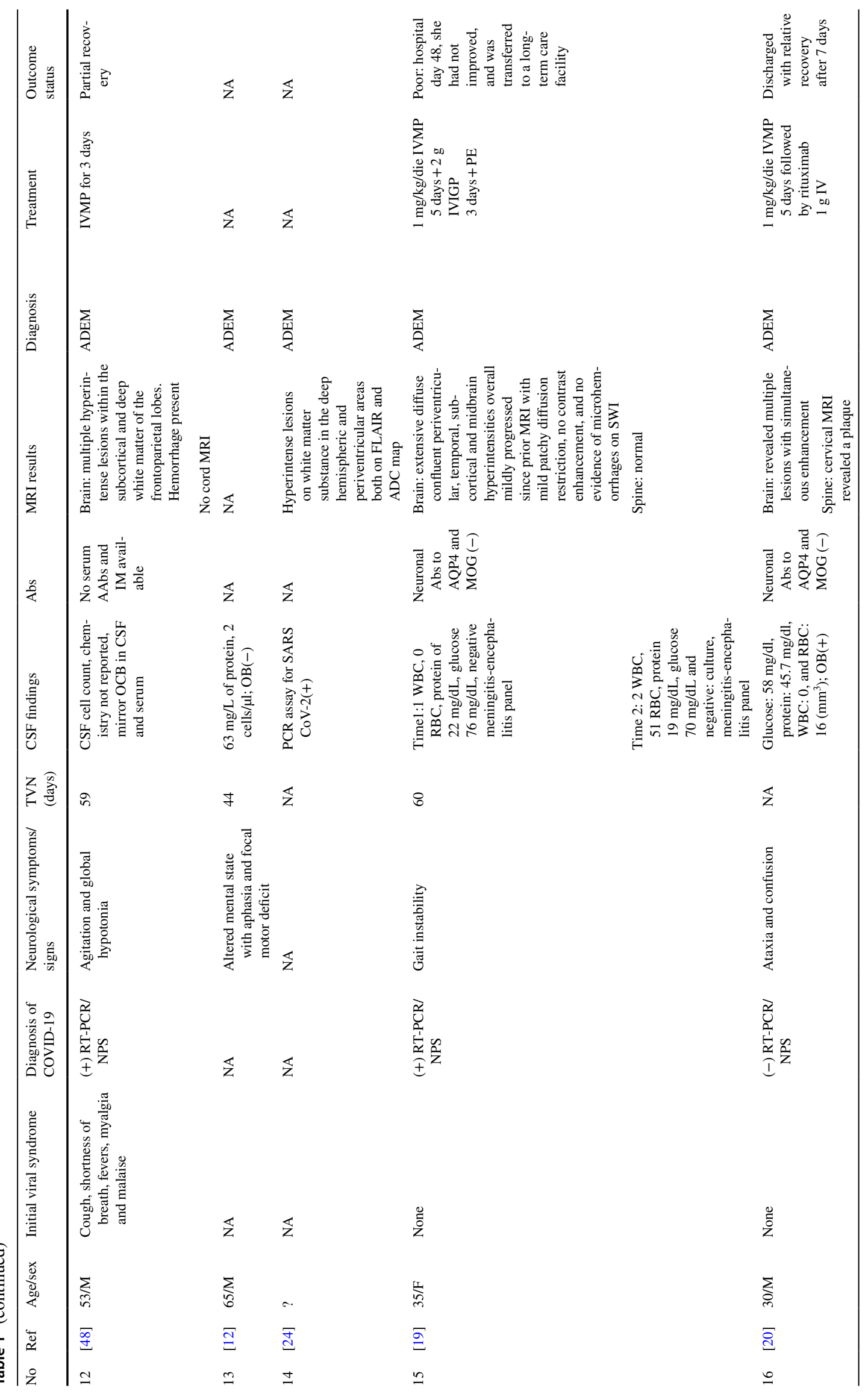




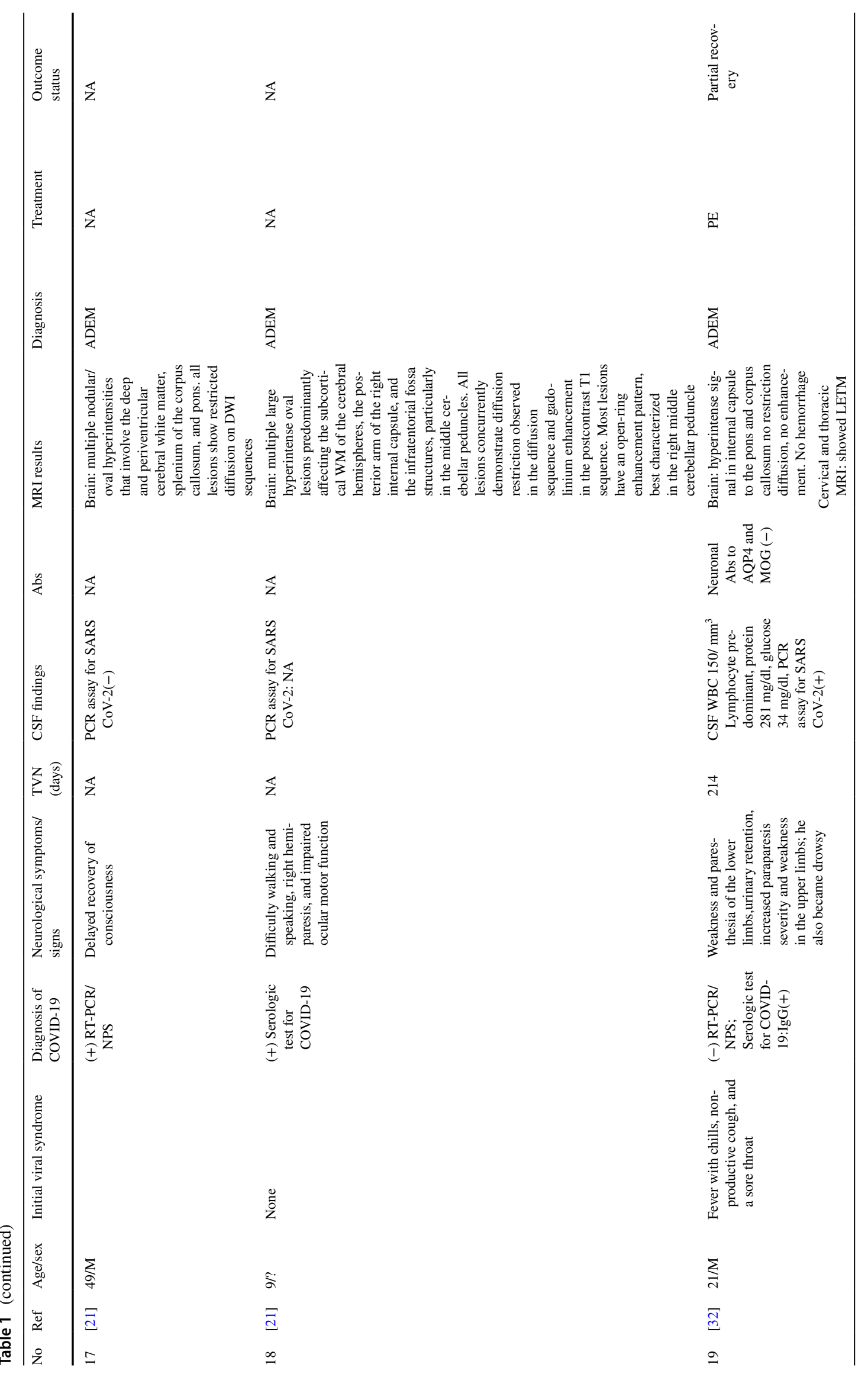




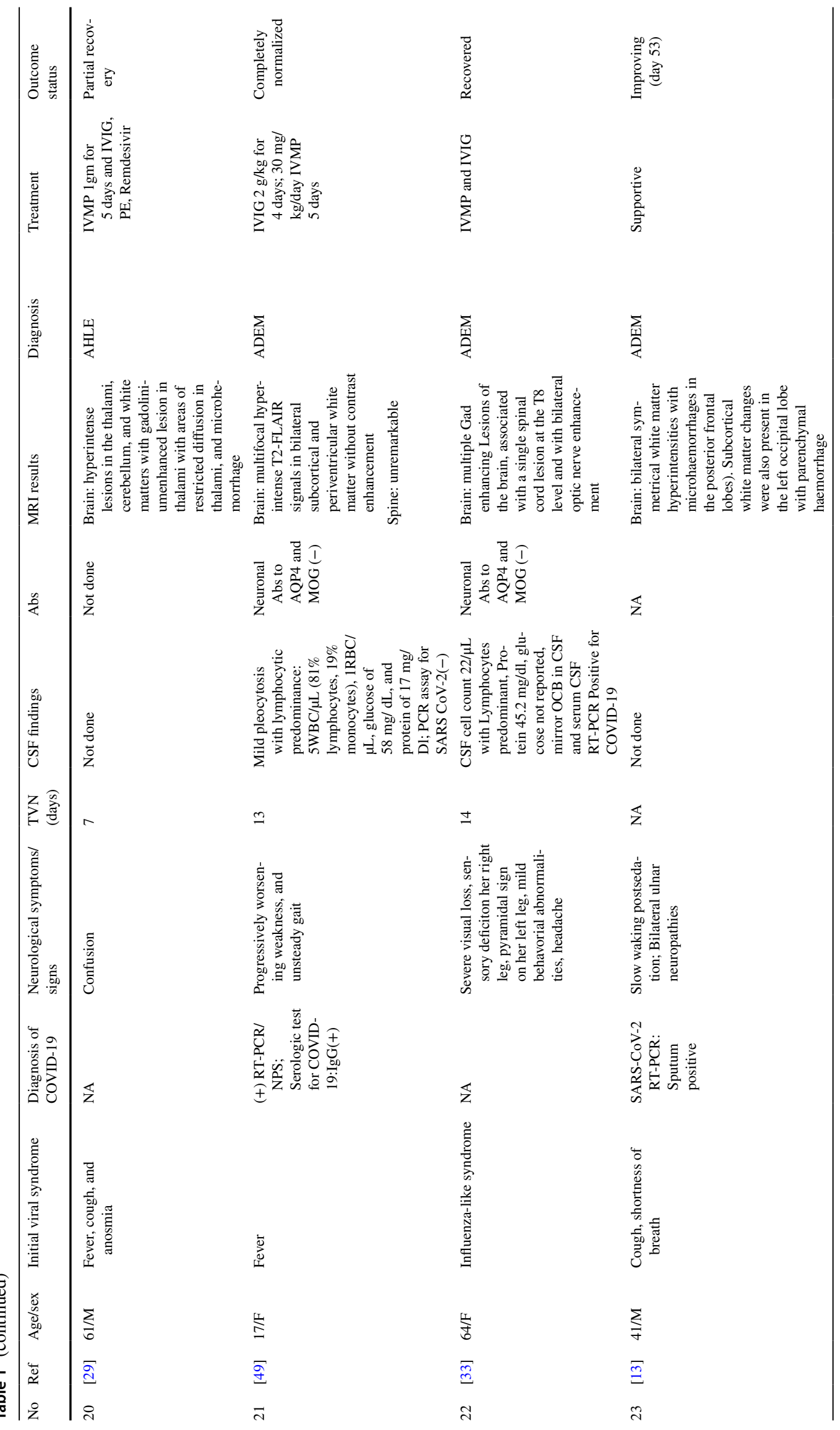




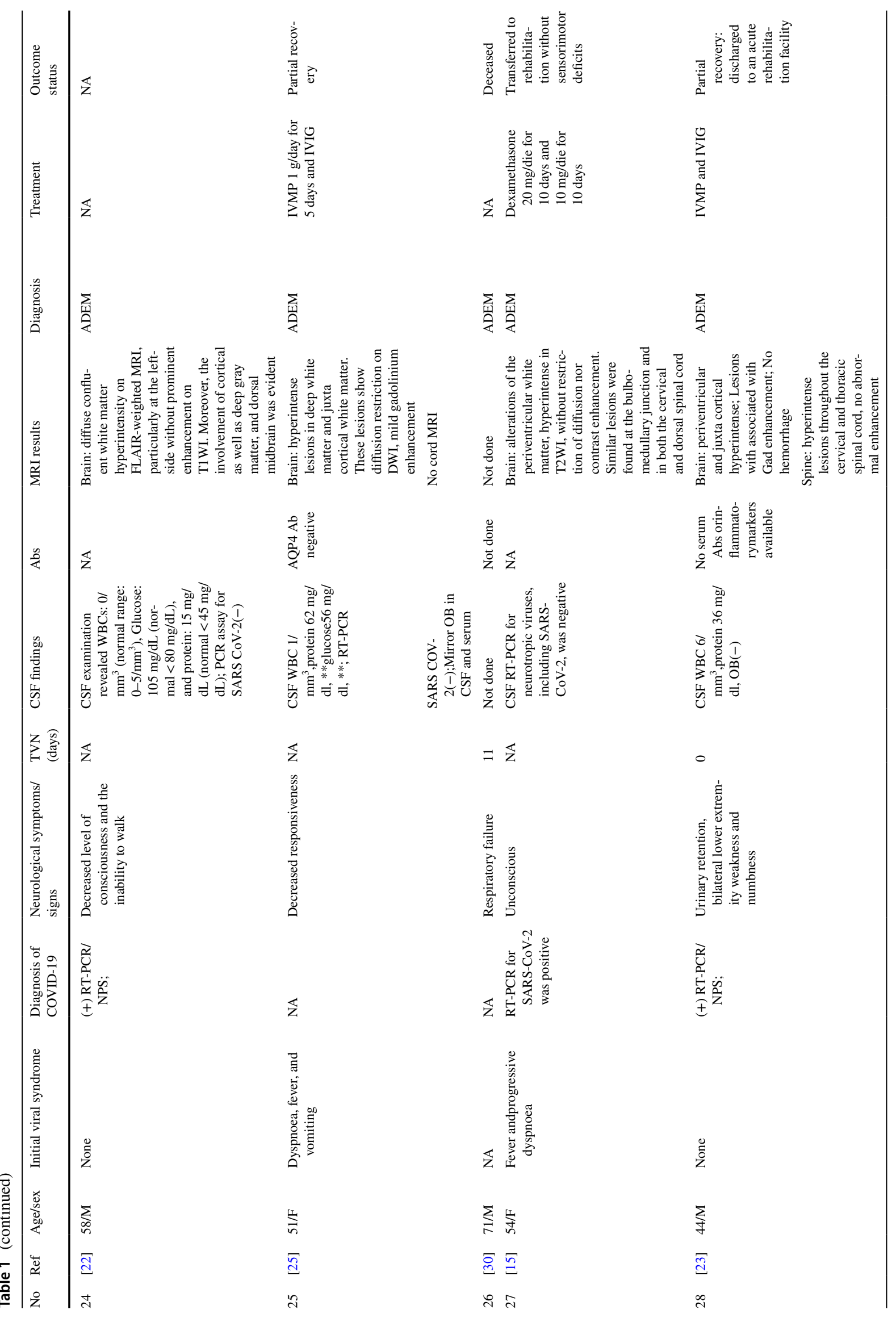




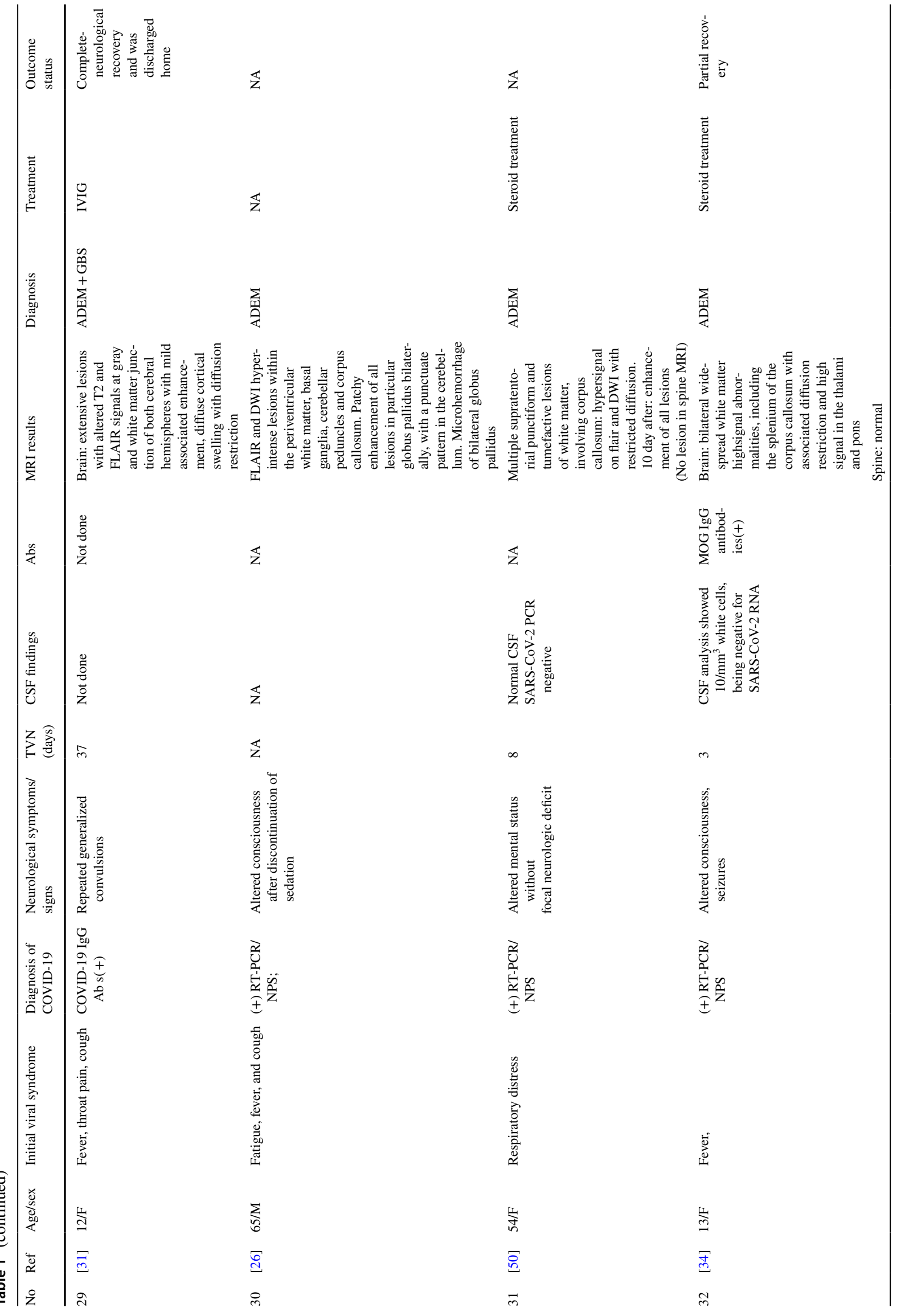




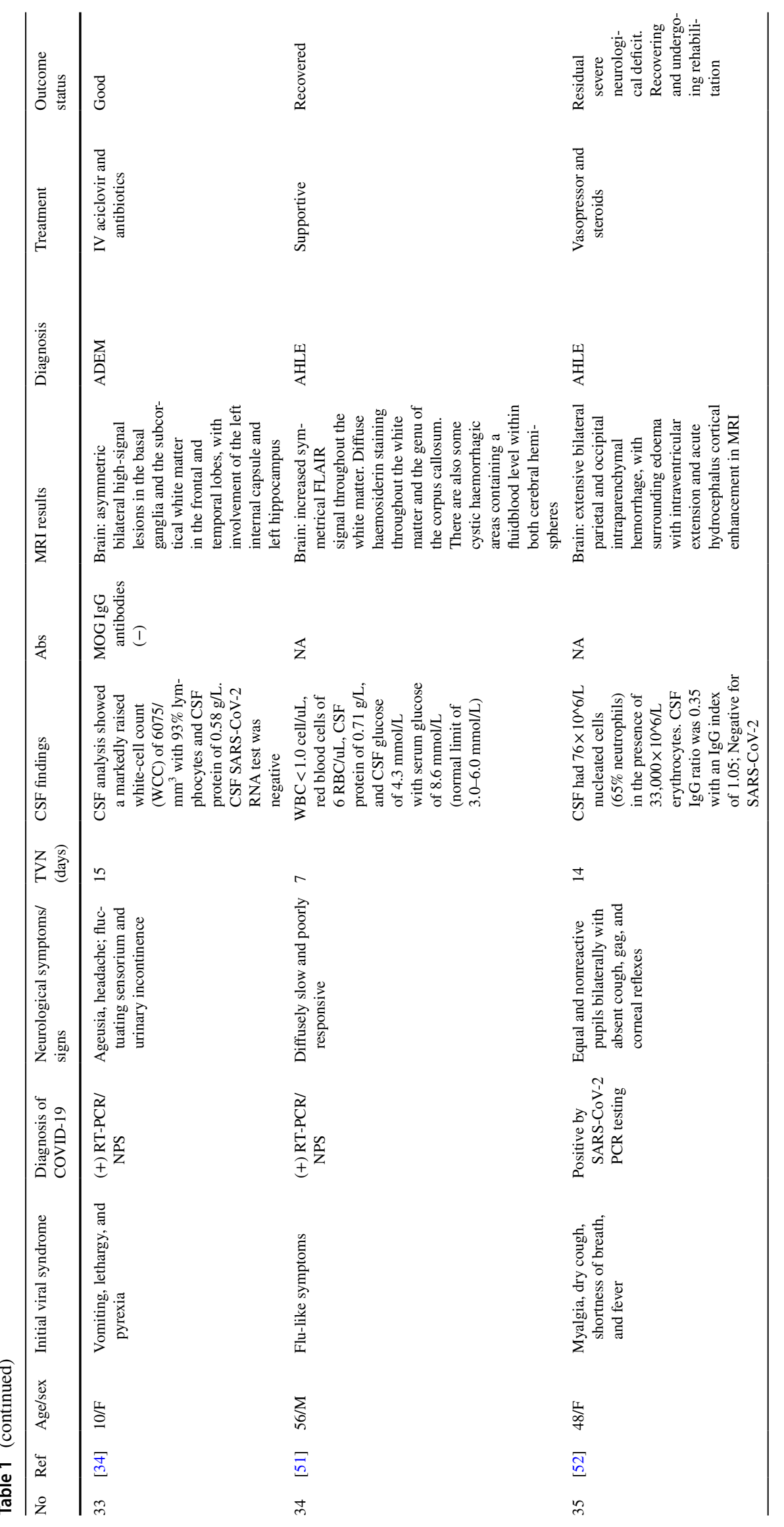




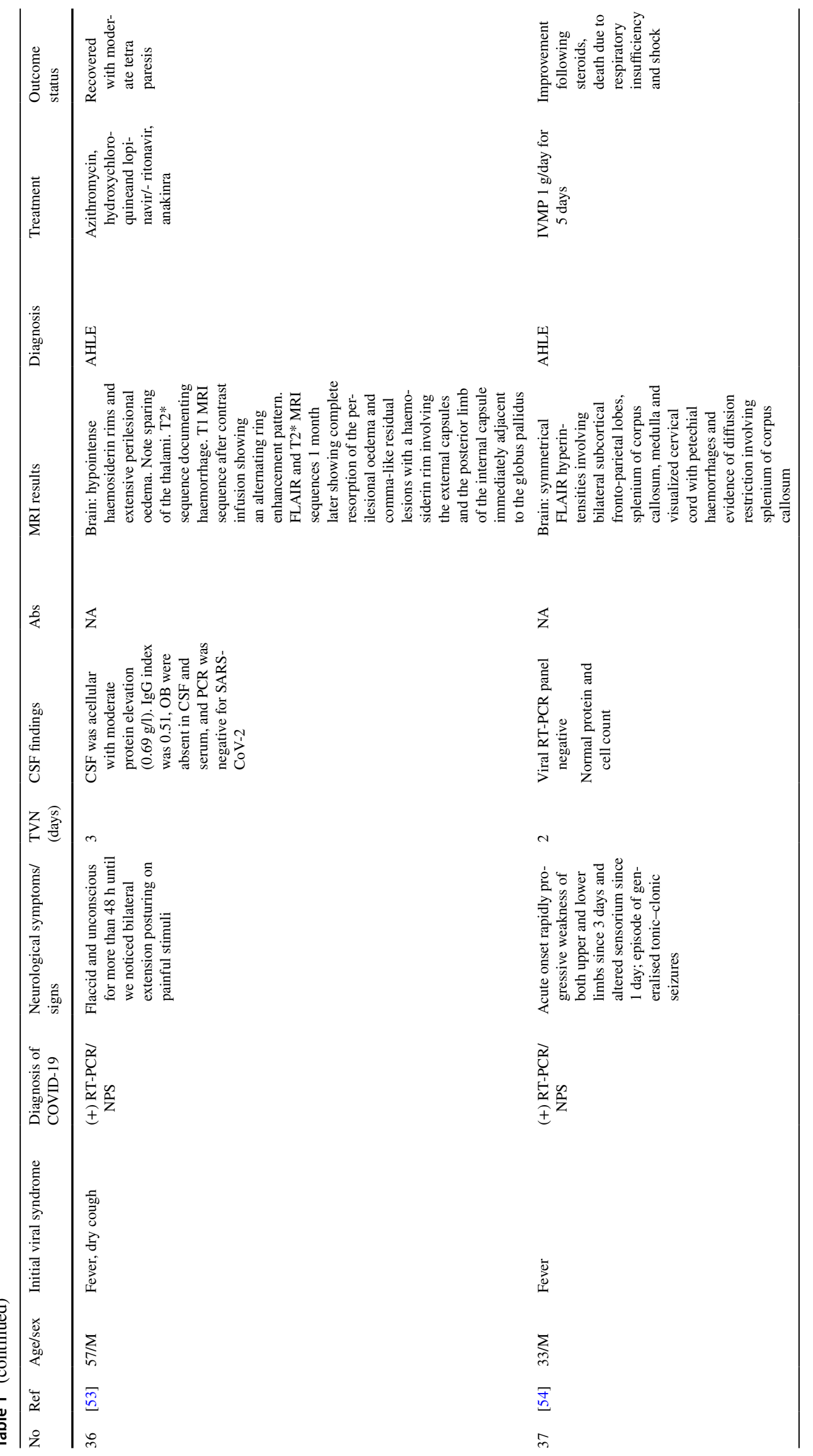

筜 Springer 


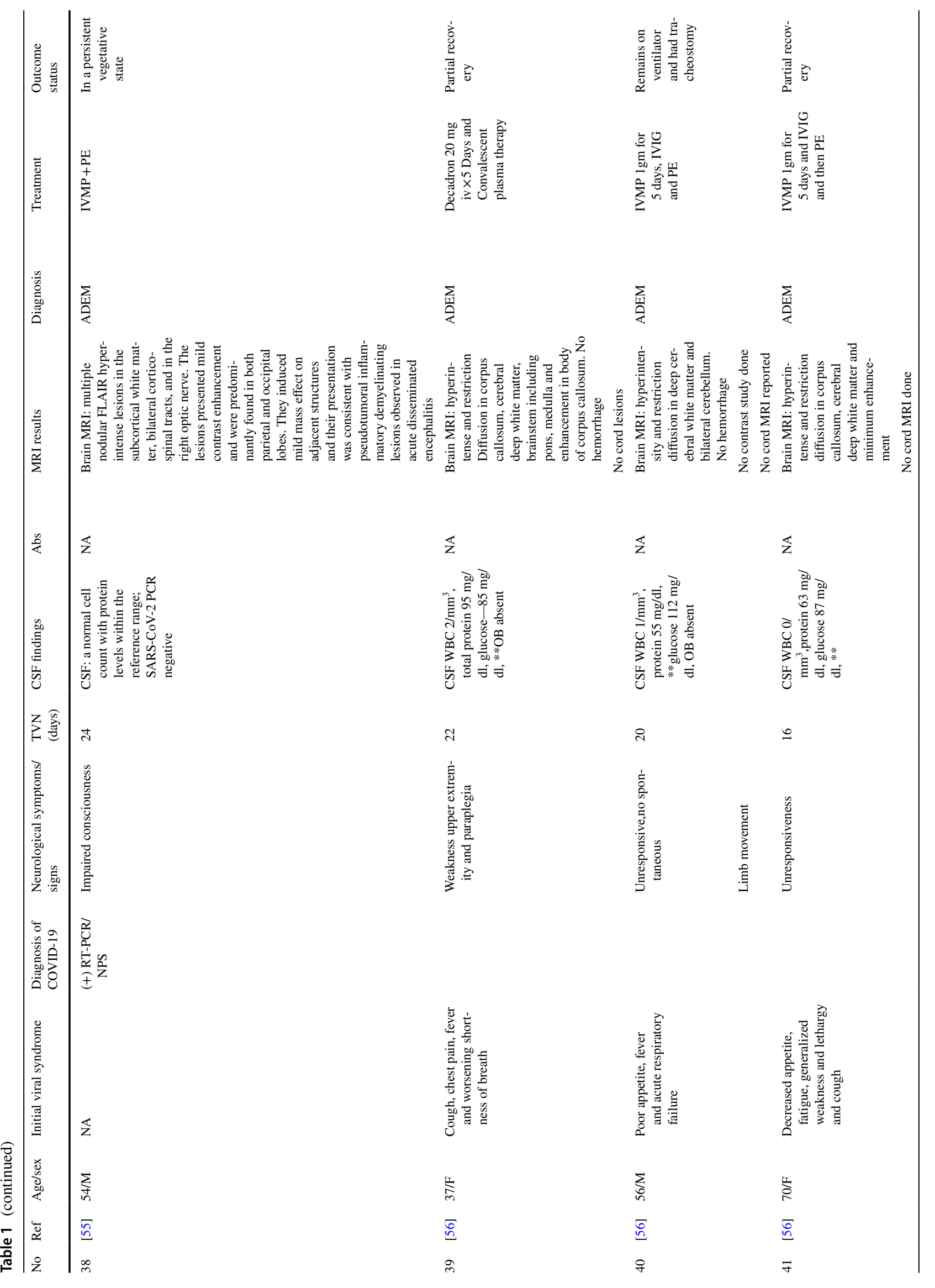




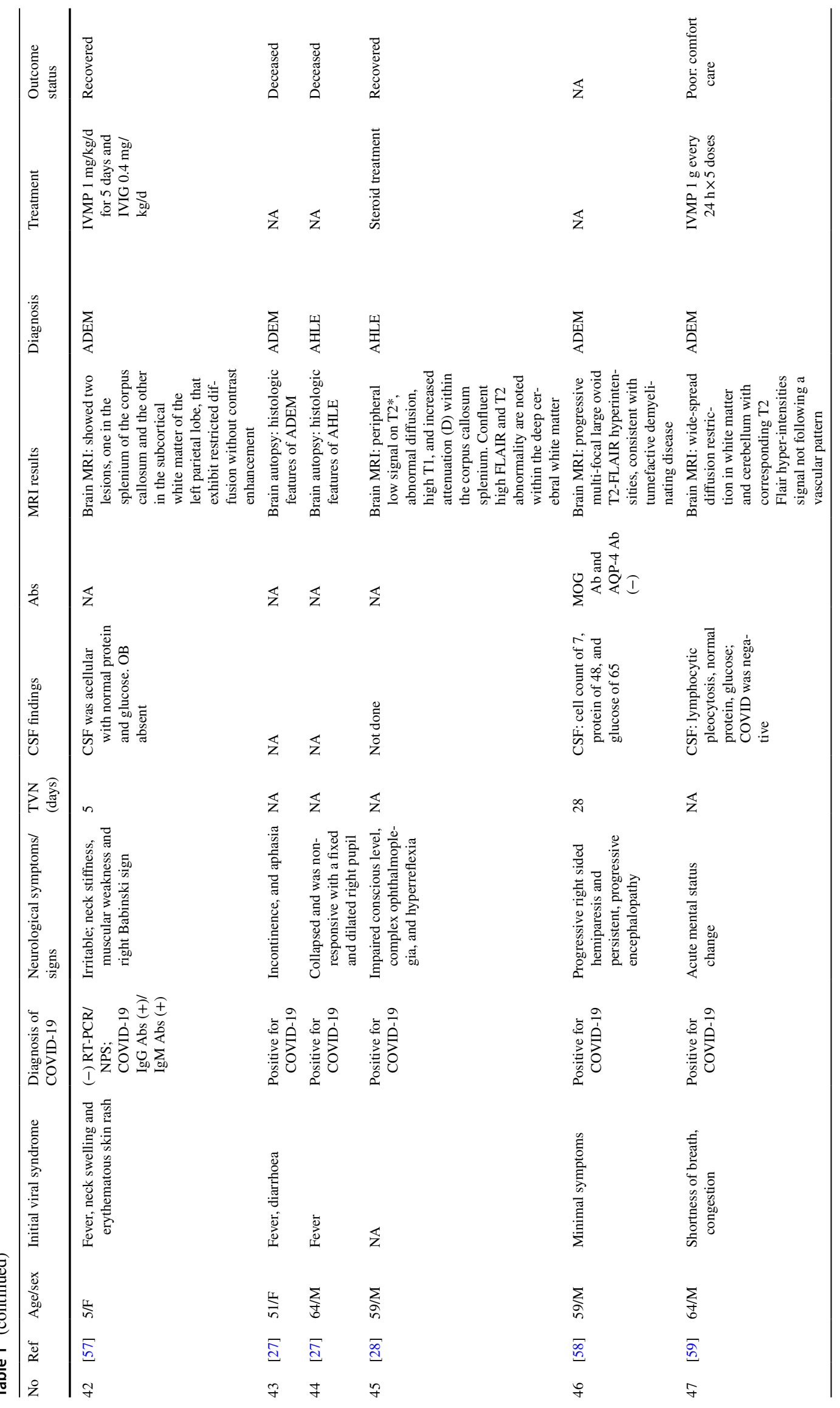




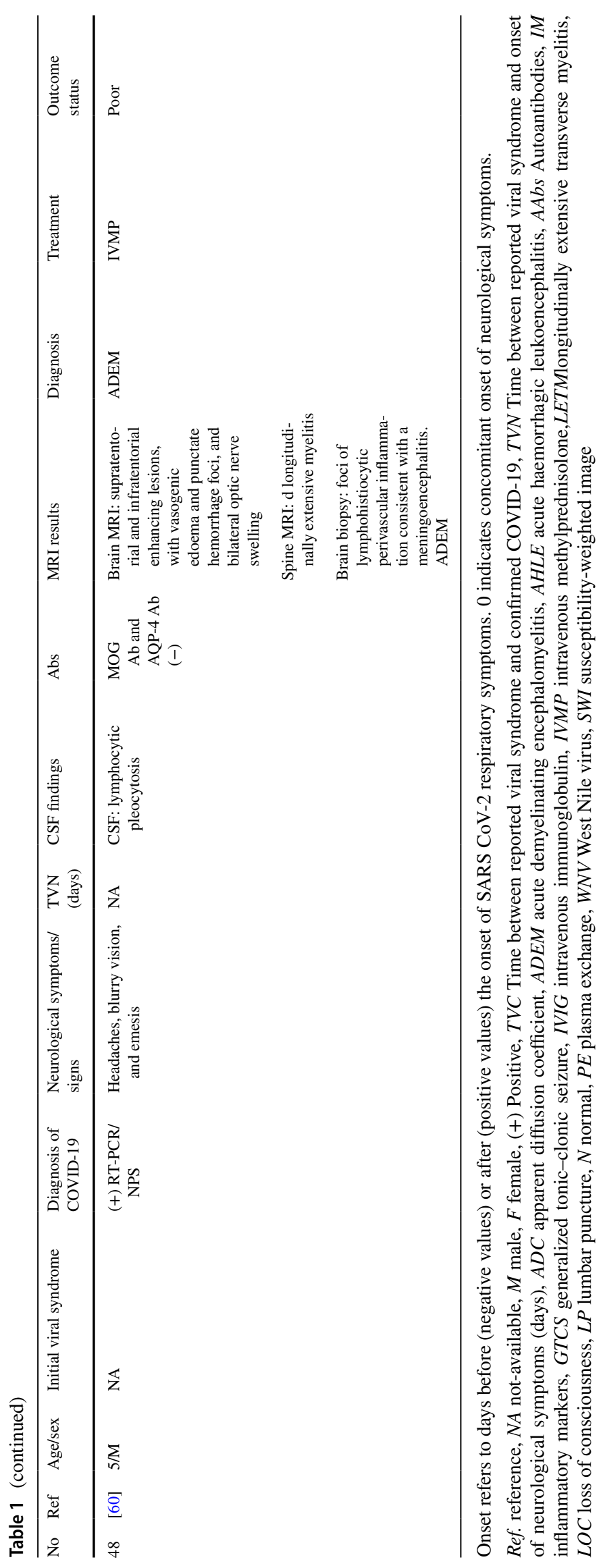


Table 2 Clinical and demographic characteristics of the 48 patients with SARS-CoV-2 and ADEM/AHLE

\begin{tabular}{|c|c|}
\hline Characteristic & Value $(n=48)$ \\
\hline ADEM-no. $(\%)$ & $34(71)$ \\
\hline AHLE-no. (\%) & $14(29)$ \\
\hline Median age (range)- $-\mathrm{yr}$ & $43.7(1.4-71)$ \\
\hline Male sex-no. $(\%)$ & $26(54.2)$ \\
\hline Famale sex-o. (\%) & $18(37.5)$ \\
\hline Adult—no./total no. (\%) & $36 / 45(80)$ \\
\hline Children-o./total no. (\%) & $9 / 45(20)$ \\
\hline \multicolumn{2}{|l|}{ Country-no./total no. (\%) } \\
\hline USA & $13 / 48(27)$ \\
\hline UK & $12 / 48(25)$ \\
\hline Italy & $5 / 48(10)$ \\
\hline Brazil & $4 / 48(8)$ \\
\hline India & $3 / 48(7)$ \\
\hline Iran & $3 / 48(6)$ \\
\hline Singapore & $3 / 48(6)$ \\
\hline France & $3 / 48(6)$ \\
\hline Canda & $1 / 48(2)$ \\
\hline Greece & $1 / 48(2)$ \\
\hline $\begin{array}{l}\text { General symptoms before the onset of the ADEM- } \\
\text { no./total no. }(\%)\end{array}$ & $35 / 48(73)$ \\
\hline Cough & $13 / 35(37)$ \\
\hline Fever & $23 / 35(66)$ \\
\hline Dyspnoea/hypoxia/Short of breath & $11 / 35(31)$ \\
\hline Myalgia & $5 / 35(14)$ \\
\hline Lethargy & $3 / 35(9)$ \\
\hline Fatigue & $4 / 35(11)$ \\
\hline Anosmia/hyposmia & $6 / 35(17)$ \\
\hline Rash & $2 / 35(6)$ \\
\hline $\begin{array}{l}\text { SARS-CoV-2 infection diagnostic categor -no./ } \\
\text { total no. }(\%)\end{array}$ & $31 / 48(64.5)$ \\
\hline Nasopharyngeal swab/PT-PCR & $23 / 31(74)$ \\
\hline Positive & $18 / 23(78)$ \\
\hline Negative & $5 / 23(21)$ \\
\hline Sputum/PT-PCR & $1 / 31(3)$ \\
\hline SARS-CoV-2 IgG (serum) & 3/31 (10) \\
\hline
\end{tabular}

in 16 patients $(24.4 \%)$ [8, 11, 13, 15, 18, 20, 22, 24-28]. COVID-19 symptoms began concurrent in one case [23]. The mean interval between onset of COVID-19 and ADEM symptoms in the remaining 31 patients was a mean 24.7 days (range 1-214 days).The most prominent reported clinical features are those of acute meningoencephalitis, including encephalopathy (59\%), headache (15\%), seizures (11\%) and fever (66\%) (Table 3). Other clinical manifestations at onset included sensory symptoms $(11 \%, 5 / 46)$, hemiplegia $(8.7 \%, 4 / 46)$, leg weakness $(8 \%, 3 / 46)$, tetraparesis $(4 \%, 2 / 46)$, arm weakness $(4 \%, 2 / 46)$,facial weakness $(4 \%, 2 / 46)$, hyporeflexia or areflexia $(4 \%, 2 / 46)$. Gait ataxia is the most another commonly reported clinical features of SARS-CoV-2-related ADEM (13\%, 6/46).

\section{Results of CSF, biochemical, and neuroimaging investigations}

CSF was examined in all $(81.0 \%, 39 / 48)$ except six of the patients $[11,13,29-31]$, and was not reported in three patients [26, 27]. Increased protein level were present in 15 patients $(38 \%, 15 / 39)$, and normal protein level were present in 13 patients $(33 \%, 13 / 39)$ with a median CSF protein of $376.0 \mathrm{mg} / \mathrm{dl}$ (min: 15, max: $2340 \mathrm{mg} / \mathrm{dl}$ ) (Tables 1 and 3).The pleocytosis was evident in $12 / 31$ cases (39\%). The search for the viral RNA in CSF was positive in three patients $(14.0 \%, 3 / 22)[24,32,33]$ out of all 22 cases in whom was done. AQP4 antibodies were tested in 19 patients, being negative in all. MOG antibodies were searched in 19 patients, being positive in one case [34]. Furthermore, CSF SARS-CoV-2 RNA was not reported or not calculable in 23 patients.

In 44 patients $(92 \%, 44 / 48)$, head MRI was performed. The deep white matter is the most frequently involved (43\%, $19 / 44)$, followed by corpus callosum $(32 \%, 14 / 44)$ and subcortical white matter $(23 \%, 10 / 44)$. Brainstem is another frequently involved $(20 \%, 9 / 44)$. The brain lesions occurring in SARS-CoV-2-ADEM involve the periventricular white matter relatively frequently $(18 \%, 8 / 44)$. The cerebellum is less frequently involved (14\%, 6/44) (Tables 1 and 2), often symmetrically [9], while deep gray matter are present to a lesser extent $(5 \%, 2 / 39)$. Contrast enhancement was reported in 17 cases $(89 \%, 17 / 19)$. Spinal MRI scans were performed in a minority of the patients $(12.5 \%, 6 / 48)$.

\section{Management of SARS-CoV-2-ADEM and patient outcomes}

All the patients except ten $[12,21,22,24,26,27,30]$ were treated with specific treatment $(79.0 \%, 38 / 48) .23$ patients were treated with intravenous methylprednisolone (IVMP) $(61 \%, 23 / 38) 0.13$ patients were treated with intravenous immunoglobulin (IVIg) $(34 \%, 13 / 38)$; and five received plasma exchange $(13 \%, 5 / 38)$. Eleven received combined IVMP and IVIg $(29 \%, 11 / 38) .31(64 \%)$ of patients had a poor outcome on discharge from hospital. Five (10.4\%) patients died in hospital.

\section{Discussion}

In current analysis, we identified and reviewed a total of 48 cases of ADEM with COVID-19 from 37 studies identified worldwide through different case series and reports. The cases were categorized into two groups for further statistical 
Table 3 Clinical and Laboratory Findings in the 48 Patients with SARS-CoV-2 and ADEM/ AHLE
Characteristic

Value $(n=48)$

Subtype of ADEM-no./total no. (\%)

ADEM

$34 / 48(71)$

AHLE

Duration, median (range), days

$14 / 48(29)$

37 (84)

Time between reported viral syndrome and onset of neurological symptoms $(n=31)$

$25(1-214)$

Signs and symptoms of neurologic illness-no./total no. (\%)

Low conscious level

$46 / 48(96)$

Headache

27/46 (59)

$7 / 46(15)$

Gait ataxia

Seizure

Abnormal sensation

Hemiplegia

$6 / 46(13)$

$5 / 46(11)$

$5 / 46(11)$

$4 / 46(9)$

Leg weakness

$3 / 46(7)$

Urinary disturbance

$4 / 46(9)$

Tetraparesis

$2 / 46(4)$

Facial weakness

$2 / 46$ (4)

$2 / 46(4)$

Hyporeflexia or areflexia

$2 / 46(4)$

Facial paresthesia

$1 / 46(2)$

$39 / 48(81)$

$15 / 39(38)$

$13 / 39(33)$

$376(15-2340)$

$12 / 31(39)$

$18 / 31(58)$

$3 / 22(14)$

$19 / 22(86)$

PCR for SARS-CoV-2 on CSF (Negative)—no./total no. (\%)

$13 / 19(68)$

Negative-no./total no. (\%)

$0 / 19(0)$

Positive-no./total no. (\%)

$12 / 19(63)$

Negative-no./total no. (\%)

$1 / 19(5)$

MRI abnormalities

Brain-no./total no. (\%)

44/48(92)

Deep white matter

19/44 (43)

$10 / 44(23)$

$8 / 44(18)$

$14 / 44(32)$

$2 / 44(5)$

$9 / 44(20)$

$6 / 44(14)$

$12 / 44(27)$

$6 / 10(60)$

$6 / 10(60)$

$1 / 10(10)$

$17 / 19(89)$

Gadolinium enhancement- no./total no. (\%)

$23 / 38(61)$

$13 / 38(34)$

$5 / 38(13)$ 
Table 3 (continued)

\begin{tabular}{lc}
\hline Characteristic & Value $(n=48)$ \\
\hline IVIg + IVMP-no./total no. (\%) & $11 / 38(29)$ \\
IVIg + IVMP+PE-no./total no. (\%) & $4 / 38(11)$ \\
Not-available-no./total no. (\%) & $10 / 48(21)$ \\
Outcome and prognosis & \\
Good-no. (\%) & $7 / 48(15)$ \\
Poor-no. (\%) & $31 / 48(64)$ \\
Dead-no. (\%) & $5 / 48(10.4)$ \\
Not-available-no./total no. (\%) & $11 / 48(23)$ \\
\hline
\end{tabular}

$P E$ plasma exchange; IVIg intravenous immunoglobulin

analysis, "ADEM" versus "AHLE". The novel addition to our review was for the first time reviewed clinical features, results of diagnostic investigations, and outcome in 48 cases of COVID-19-associated ADEM spectrum.

Classic ADEM is an immune-mediated, inflammatory demyelinating disease of the central nervous system (CNS) that usually affects children and young adults after an infection or vaccination $[9,35]$. The mean age of onset of classic ADEM is between 3.6 and 7 years [36]. We found significant differences between COVID-19-associated ADEM and classic ADEM in age at onset; the mean age for COVID-19-associated ADEM was 44 years. In the present study, mean age at onset in patients with COVID-19-associated ADEM largely older that of classic ADEM subjects, indicating that an adult age range might be affected (Table 4). Although ADEM has no obvious gender predominance, a slight male prevalence is reported in a few paediatric series [37]. We found a slightly higher prevalence of COVID-19-associated ADEM in males compared to females (male:female ratio is 1.4:1), which is consistent with the literature in general.

In the typical presentation of ADEM, neurological symptoms develop 7-14 days following an infection and may involve headache, emesis, meningismus, and alterations in behaviour and level of alertness s [35]. Common neurological exam findings include altered mental status, ataxia, and extremity weakness. A latency period between the onset of the ADEM symptoms and onset of COVID-19 has been reported in different papers (Table 1). The present cohort has shown an average latency of 25 days from the onset of COVID symptoms to the presentation of ADEM. The mean latency ranged between a duration of 0 to 214 days. We did not found significant differences between COVID-19-associated ADEM vs. classic ADEM in neurological symptoms and signs at onset.

The diagnosis of ADEM is based on a combination of clinical features, supported by MRI findings. Brain MRI T2-weighted and fluid-attenuated inversion recovery (FLAIR) images typically demonstrate multiple hyperintense bilateral, asymmetric patchy and poorly marginated lesions [37], which typically involve the subcortical and deep white matter $[9,37-40]$. The brain lesions occurring in ADEM more frequently affect the deep gray matter and cortex [41] and less frequently involve the periventricular white matter [42] and corpus callosum [41].The deep gray matter is frequently involved (40-60\%), often symmetrically [43]. In our population, most common brain lesions resemble those of classic ADEM, i.e. the distribution of lesions more frequently affect subcortical and deep white matter (Tables 3 and 4). Compared to the lesions observed in classic ADEM, the brain lesions occurring in COVID19-associated ADEM more frequently involve the periventricular white matter (18\%) and corpus callosum (32\%), and less frequently affect the deep gray matter (5\% vs. 40-60\%). The reported frequency of gadolinium-enhancing lesions in classic ADEM is highly variable between studies (10-95\%) [43], largely overlapping with the percentages in our cohort (89\%).

CSF examination reveals inflammatory findings in most ADEM patients [44], consisting of elevated protein levels (15-60\%) and lymphocytic pleocytosis (25-65\%). In our population, increased protein level was present in 38\% patients, and normal protein level were present in 33\% patients. The pleocytosis was evident in $39 \%$ cases. These results indicated that we did not found an obvious discrepancy concerning CSF findings between classic ADEM and COVID-19-associated ADEM. First-line acute treatment of classic ADEM generally consists of IVMP at a dose of $30 \mathrm{mg} / \mathrm{kg} /$ day (maximum $1000 \mathrm{mg} /$ day) for 3-5 days, followed by an oral prednisone taper for 4-6 weeks [9]. 61\% patients were treated with IVMP, which overlapping with the percentages in classic ADEM [43]. The use of IVIg is usually considered a second-line treatment option for ADEM patients who do not respond to or who deteriorate after intravenous steroids, which has proven effective in about $40-50 \%$ of steroid-resistant patients [43]. 34\% of patients were treated with IVIg, indicating that a high percentage use of IVIg for the treatment of COVID-19-associated ADEM.

Patients with classic ADEM usually have a good outcome with a complete recovery. The outcome seems to be better in children than in young adults, especially for the disease 
Table 4 Comparation of clinical characteristics of SARS-CoV-2-ADEM with typical ADEM

\begin{tabular}{|c|c|c|}
\hline Characteristic & SARS-CoV-2-ADEM & Typical ADEM \\
\hline Onset age preponderance & $\begin{array}{l}\text { Predominantly adult, median age } \\
44 \mathrm{yr}(1.4-71 \mathrm{yr})\end{array}$ & More commonly affects children \\
\hline Male:female ratio & $1.4: 1$ & $1: 1$ \\
\hline Prodromal symptoms & $\begin{array}{l}\text { Fever, cough, dyspnoea, anosmia/ } \\
\text { hyposmia, myalgia, fatigue }\end{array}$ & Fever, headache, malaise, nausea, and vomiting \\
\hline Duration(days) & 25 & $7-14$ \\
\hline \multicolumn{3}{|l|}{ Symptoms/signs of acute phase } \\
\hline Encephalopathy & $59 \%$ & $100 \%[45]$ \\
\hline Seizures & $11 \%$ & $12-50 \%[45] ; 13-46 \%[43]$ \\
\hline Cranial nerve deficits & $15 \%$ & $18-39 \%[45]$ \\
\hline Pyramidal signs & $5 \%$ & $18-60 \%[45]$ \\
\hline Sensory deficits & $13 \%$ & $0-9 \%[45] ; 28-65 \%$ [43] \\
\hline Cerebellar signs/ataxia & $15 \%$ & $36-47 \%[45]$ \\
\hline Urinary disturbance & $8 \%$ & $6-25 \%[45]$ \\
\hline \multicolumn{3}{|l|}{ MRI brain } \\
\hline Brain—no./total no. (\%) & $92 \%$ & $60-100 \%$ [43] \\
\hline Deep/Subcortical white matter & $43 \% / 23 \%$ & $\begin{array}{l}\text { Typically, lesions occur in the deep and subcortical white matter while } \\
\text { sparing periventricular white matter }\end{array}$ \\
\hline Periventricular white matter & $18 \%$ & $\begin{array}{l}\text { Less frequently involve the periventricular white matter [42], and more } \\
\text { frequently affect the deep gray matter and cortex [42] }\end{array}$ \\
\hline Corpus callosum & $32 \%$ & Less frequently involve corpus callosum [41] \\
\hline Deep gray matter & $5 \%$ & $40-60 \%$,often symmetrically [43] \\
\hline Brainstem & $20 \%$ & $17-63 \%[43]$ \\
\hline Cerebellum & $14 \%$ & $27-41 \%[43]$ \\
\hline Microhemorrhage & $27 \%$ & Not reported \\
\hline Gadolinium-enhancing lesions & $89 \%$ & $0-95 \%[43]$ \\
\hline Spinal cord involvement & $60 \%$ & $10-100 \%[43]$ \\
\hline Outcome and prognosis & $64 \%$ poor with a dead rate of $10 \%$ & $\begin{array}{l}\text { Good: usually have a good outcome with a complete recovery. The } \\
\text { outcome seems to be better in children than in young adults }\end{array}$ \\
\hline \multicolumn{3}{|l|}{ CSF analysis } \\
\hline Increased protein level & $38 \%$ & $16-97 \%[43]$ \\
\hline Increased white-cell count level & $39 \%$ & $25-65 \%[43]$ \\
\hline $\mathrm{OB}(+)$ & $35 \%$ & $\sim 29 \%[43]$ \\
\hline Steroid treatment & $61 \%$ & $46-95 \%[43]$ \\
\hline IVIG & $34 \%$ & $\begin{array}{l}\text { Second-line treatment option for ADEM patients who do not respond to } \\
\text { or who deteriorate after intravenous steroids [61]. has proven effective } \\
\text { in about } 40-50 \% \text { of steroid-resistant patients [43] }\end{array}$ \\
\hline $\mathrm{PE}$ & $13 \%$ & $\begin{array}{l}\text { Occasionally been used as a second-line therapy in severe cases. The } \\
\text { effectiveness of PE is estimated at around } 40 \% \text { [62], which is compa- } \\
\text { rable to the effectiveness of IVIg }\end{array}$ \\
\hline ICU management & $50 \%$ & $15 \%[63]$ \\
\hline Mortality & $10 \%$ & $\sim 5 \%[43]$ \\
\hline Full recovery & $15 \%$ & $47-89 \%[43]$ \\
\hline
\end{tabular}

course, recovery, and mean duration of hospitalization [45]. Unlike typical ADEM, most of COVID-19-related ADEM have a relatively poor outcome, with mortality rates of $10 \%$ (Table 4). In analogy to classic ADEM, only 15\% COVID19-associated ADEM subjects have a full recovery (15\% VS 47-89\%). In this regard, cases with COVID-19-associated ADEM need a higher rate of ICU management.
Our study had several strengths. Major strengths of our review are the inclusion of a high number of patients, together with an in-depth analysis of the clinical features of COVID-19-associated ADEM for the first time. This is among the first studies focused on comparing the clinical presentation, management and outcomes in COVID-19 patients who were diagnosed with ADEM, highlighting on 
differences with classic ADEM. Our study should be considered in light of several limitations. First, cases included in this review were identified through a comprehensive search of databases using a systematic search strategy. There is a possibility of missing out new upcoming studies because of the evolving nature of the COVID-19 pandemic. Second limitation associated with this systematic review is the concern notably restriction of the search to the PubMed and Web of Science, inclusion of articles published only in English, and heterogeneity of included studies.

\section{Conclusion}

In conclusion, based on the systematic review of 48 cases, we showed the clinical picture of COVID-19-associated ADEM, and revealed that although rare, ADEM can be associated with SARS-CoV-2 infection. SARS-CoV-2-ADEM seems to share most features of classic ADEM, with a moderate discrepancies from the classical ADEM. In analogy to classic ADEM, COVID-19-associated ADEM have a more longer duration between the onset of the antecedent infective symptoms and the start of ADEM symptoms, the older age distribution of the patients, relatively poor outcome, a lower full recovery rate, a more frequently brain lesions involved the periventricular white matter and corpus callosum, and less frequently affected the deep gray matter.

Acknowledgements This work was supported in part by the National Natural Science Foundation of China (61971011), Science Foundation of AMHT (2020YK02), Science Foundation of CASIC (2020LCYL-009), Science Foundation of ASCH(YN202104), Cultivation plan of Scientific Research Committee for health development of Haidian District of Beijing (HP2021-19-50701), Natural Science Foundation of Inner Mongolia Autonomous Region(IMAR) (2018MS08046; 2020MS08175; 2021MS08131), and Program for Young Talents of Science and Technology in Universities of IMAR (NJYT-17-B23).

Author contributions Conceptualization: all authors; methodology, formal analysis, and investigation: YW HW; writing-original draft preparation: YW and HW; writing-review and editing: all authors; supervision: YW and Hongquan Wang.

\section{Declarations}

Conflicts of interest The authors declare no financial or other conflicts of interest.

\section{References}

1. Huang C, Wang Y, Li X, Ren L, Zhao J, Hu Y, Zhang L, Fan G, Xu J, Gu X, Cheng Z, Yu T, Xia J, Wei Y, Wu W, Xie X, Yin W, Li H, Liu M, Xiao Y, Gao H, Guo L, Xie J, Wang G, Jiang R, Gao Z, Jin Q, Wang J, Cao B (2020) Clinical features of patients infected with 2019 novel coronavirus in Wuhan, China. Lancet 395:497-506
2. Mao L, Jin H, Wang M, Hu Y, Chen S, He Q, Chang J, Hong C, Zhou Y, Wang D, Miao X, Li Y, Hu B (2020) Neurologic manifestations of hospitalized patients with coronavirus disease 2019 in Wuhan, China. JAMA Neurol 77:683-690

3. Camargo-Martínez W, Lozada-Martínez I, Escobar-Collazos A, Navarro-Coronado A, Moscote-Salazar L, Pacheco-Hernández A, Janjua T, Bosque-Varela P (2021) Post-COVID 19 neurological syndrome: implications for sequelae's treatment. J Clin Neurosci $88: 219-225$

4. Elmashala A, Chopra S, Garg A (2020) The neurologic manifestations of coronavirus disease 2019. J Neurol Res 10:107-112

5. Gaddam S (2020) Implications of COVID-19 in neurological disorders. J Neurol Res 10:160-163

6. Koralnik IJ, Tyler KL (2020) COVID-19: a global threat to the nervous system. Ann Neurol 88:1-11

7. Nordvig AS, Fong KT, Willey JZ, Thakur KT, Boehme AK, Vargas WS, Smith CJ, Elkind M (2021) Potential neurologic manifestations of COVID-19. Neurol Clin Pract 11:e135-135e146

8. Li X, Wang Y, Wang H, Wang Y (2021) SARS-CoV-2-associated Guillain-Barré syndrome is a para-infectious disease. QJM. https://doi.org/10.1093/qjmed/hcab157

9. Pohl D, Alper G, Van Haren K, Kornberg AJ, Lucchinetti CF, Tenembaum S, Belman AL (2016) Acute disseminated encephalomyelitis: updates on an inflammatory CNS syndrome. Neurology 87:S38-45

10. Sriwastava S, Tandon M, Podury S, Prasad A, Wen S, Guthrie G, Kakara M, Jaiswal S, Subedi R, Elkhooly M, Lisak RP (2021) COVID-19 and neuroinflammation: a literature review of relevant neuroimaging and CSF markers in central nervous system inflammatory disorders from SARS-COV2. J Neurol. https://doi.org/10. 1007/s00415-021-10611-9

11. Koh JS, De Silva DA, Quek A, Chiew HJ, Tu TM, Seet C, Hoe R, Saini M, Hui AC, Angon J, Ker JR, Yong MH, Goh Y, Yu WY, Lim T, Tan B, Ng K, Yeo L, Pang YZ, Prakash KM, Ahmad A, Thomas T, Lye D, Tan K, Umapathi T (2020) Neurology of COVID-19 in Singapore. J Neurol Sci 418:117118

12. Pilotto A, Masciocchi S, Volonghi I, Crabbio M, Magni E, De Giuli V, Caprioli F, Rifino N, Sessa M, Gennuso M, Cotelli MS, Turla M, Balducci U, Mariotto S, Ferrari S, Ciccone A, Fiacco F, Imarisio A, Risi B, Benussi A, Premi E, Focà E, Caccuri F, Leonardi M, Gasparotti R, Castelli F, Zanusso G, Pezzini A, Padovani A (2021) Clinical presentation and outcomes of severe acute respiratory syndrome coronavirus 2-related encephalitis: the ENCOVID multicenter study. J Infect Dis 223:28-37

13. Sawlani V, Scotton S, Nader K, Jen JP, Patel M, Gokani K, Denno P, Thaller M, Englezou C, Janjua U, Bowen M, Hoskote C, Veenith T, Hassan-Smith G, Jacob S (2021) COVID-19-related intracranial imaging findings: a large single-centre experience. Clin Radiol 76:108-116

14. Paterson RW, Brown RL, Benjamin L, Nortley R, Wiethoff S, Bharucha T, Jayaseelan DL, Kumar G, Raftopoulos RE, Zambreanu L, Vivekanandam V, Khoo A, Geraldes R, Chinthapalli K, Boyd E, Tuzlali H, Price G, Christofi G, Morrow J, McNamara P, McLoughlin B, Lim ST, Mehta PR, Levee V, Keddie S, Yong W, Trip SA, Foulkes A, Hotton G, Miller TD, Everitt AD, Carswell C, Davies N, Yoong M, Attwell D, Sreedharan J, Silber E, Schott JM, Chandratheva A, Perry RJ, Simister R, Checkley A, Longley N, Farmer SF, Carletti F, Houlihan C, Thom M, Lunn MP, Spillane J, Howard R, Vincent A, Werring DJ, Hoskote C, Jäger HR, Manji H, Zandi MS (2020) The emerging spectrum of COVID-19 neurology: clinical, radiological and laboratory findings. Brain 143:3104-3120

15. Zanin L, Saraceno G, Panciani PP, Renisi G, Signorini L, Migliorati K, Fontanella MM (2020) SARS-CoV-2 can induce brain and spine demyelinating lesions. Acta Neurochir (Wien) 162:1491-1494 
16. Moher D, Shamseer L, Clarke M, Ghersi D, Liberati A, Petticrew M, Shekelle P, Stewart LA (2015) Preferred reporting items for systematic review and meta-analysis protocols (PRISMA-P) 2015 statement. Syst Rev 4:1

17. Shamseer L, Moher D, Clarke M, Ghersi D, Liberati A, Petticrew M, Shekelle P, Stewart LA (2015) Preferred reporting items for systematic review and meta-analysis protocols (PRISMA-P) 2015: elaboration and explanation. BMJ 350:g7647

18. Manzo ML, Galati C, Gallo C, Santangelo G, Marino A, Guccione F, Pitino R, Raieli V (2021) ADEM post-Sars-CoV-2 infection in a pediatric patient with Fisher-Evans syndrome. Neurol Sci. https://doi.org/10.1007/s10072-021-05311-1

19. Kumar A, Olivera A, Mueller N, Howard J, Lewis A (2020) Delayed SARS-COV-2 leukoencephalopathy without severe hypoxia. J Neurol Sci 418:117146

20. Shahmirzaei S, Naser Moghadasi A (2021) Association of COVID-19 and acute disseminated encephalomyelitis (ADEM) in the absence of pulmonary involvement. Autoimmun Rev 20:102753

21. Assunção FB, Fragoso DC, Donoso Scoppetta T, Martins Maia AC (2020) COVID-19-associated acute disseminated encephalomyelitis-like disease. AJNR Am J Neuroradiol 42:E21-23

22. Abdi S, Ghorbani A, Fatehi F (2020) The association of SARSCoV-2 infection and acute disseminated encephalomyelitis without prominent clinical pulmonary symptoms. J Neurol Sci 416:117001

23. Utukuri PS, Bautista A, Lignelli A, Moonis G (2020) Possible acute disseminated encephalomyelitis related to severe acute respiratory syndrome coronavirus 2 infection. AJNR Am J Neuroradiol 41:E82-82E83

24. Espíndola OM, Brandão CO, Gomes $\mathrm{Y}$, Siqueira $\mathrm{M}$, Soares $\mathrm{CN}$, Lima M, Leite A, Torezani G, Araujo A, Silva M (2021) Cerebrospinal fluid findings in neurological diseases associated with COVID-19 and insights into mechanisms of disease development. Int J Infect Dis 102:155-162

25. Parsons T, Banks S, Bae C, Gelber J, Alahmadi H, Tichauer M (2020) COVID-19-associated acute disseminated encephalomyelitis (ADEM). J Neurol 267:2799-2802

26. Hanafi R, Roger PA, Perin B, Kuchcinski G, Deleval N, Dallery F, Michel D, Hacein-Bey L, Pruvo JP, Outteryck O, Constans JM (2020) COVID-19 neurologic complication with CNS vasculitislike pattern. AJNR Am J Neuroradiol 41:1384-1387

27. Walker JM, Gilbert AR, Bieniek KF, Richardson TE (2021) COVID-19 patients with CNS complications and neuropathologic features of acute disseminated encephalomyelitis and acute hemorrhagic leukoencephalopathy. J Neuropathol Exp Neurol 80:628-631

28. Green C, Morrison H, Smith P, Golestani F, Rice C, Coulthard E, Searle J, Lyburn I (2021) Teaching neuroimages: COVID19-associated acute disseminated encephalomyelitis with corpus callosal hemorrhage. Neurology 96:e307-307e308

29. Yong MH, Chan Y, Liu J, Sanamandra SK, Kheok SW, Lim KC, Sewa DW (2020) A rare case of acute hemorrhagic leukoencephalitis in a covid-19 patient. J Neurol Sci 416:117035

30. Reichard RR, Kashani KB, Boire NA, Constantopoulos E, Guo Y, Lucchinetti CF (2020) Neuropathology of COVID-19: a spectrum of vascular and acute disseminated encephalomyelitis (ADEM)like pathology. Acta Neuropathol 140:1-6

31. Mehra B, Aggarwal V, Kumar P, Kundal M, Gupta D, Kumar A, Dugaya SK (2020) COVID-19-associated severe multisystem inflammatory syndrome in children with encephalopathy and neuropathy in an adolescent girl with the successful outcome: an unusual presentation. Indian J Crit Care Med 24:1276-1278

32. Zoghi A, Ramezani M, Roozbeh M, Darazam IA, Sahraian MA (2020) A case of possible atypical demyelinating event of the central nervous system following COVID-19. Mult Scler Relat Disord 44:102324

33. Novi G, Rossi T, Pedemonte E, Saitta L, Rolla C, Roccatagliata L, Inglese M, Farinini D (2020) Acute disseminated encephalomyelitis after SARS-CoV-2 infection. Neurol Neuroimmunol Neuroinflamm 7:e797

34. Vraka K, Ram D, West S, Chia W, Kurup P, Subramanian G, Tan HJ (2021) Two paediatric patients with encephalopathy and concurrent COVID-19 infection: two sides of the same coin. Case Rep Neurol Med 2021:6658000

35. Wang CX (2021) Assessment and management of acute disseminated encephalomyelitis (ADEM) in the pediatric patient. Paediatr Drugs 23:213-221

36. Cole J, Evans E, Mwangi M, Mar S (2019) Acute disseminated encephalomyelitis in children: an updated review based on current diagnostic criteria. Pediatr Neurol 100:26-34

37. Tenembaum S, Chamoles N, Fejerman N (2002) Acute disseminated encephalomyelitis: a long-term follow-up study of 84 pediatric patients. Neurology 59:1224-1231

38. Atzori M, Battistella PA, Perini P, Calabrese M, Fontanin M, Laverda AM, Suppiej A, Drigo P, Grossi P, Rinaldi L, Gallo P (2009) Clinical and diagnostic aspects of multiple sclerosis and acute monophasic encephalomyelitis in pediatric patients: a single centre prospective study. Mult Scler 15:363-370

39. Mikaeloff Y, Caridade G, Husson B, Suissa S, Tardieu M (2007) Acute disseminated encephalomyelitis cohort study: prognostic factors for relapse. Eur J Paediatr Neurol 11:90-95

40. Alper G, Heyman R, Wang L (2009) Multiple sclerosis and acute disseminated encephalomyelitis diagnosed in children after longterm follow-up: comparison of presenting features. Dev Med Child Neurol 51:480-486

41. de Seze J, Debouverie M, Zephir H, Lebrun C, Blanc F, Bourg V, Wiertlewski S, Pittion S, Laplaud D, Le Page E, Deschamps R, Cabre P, Pelletier J, Malikova I, Clavelou P, Jaillon V, Defer G, Labauge P, Gout O, Boulay C, Edan G, Vermersch P (2007) Acute fulminant demyelinating disease: a descriptive study of 60 patients. Arch Neurol 64:1426-1432

42. Dale RC, de Sousa C, Chong WK, Cox TC, Harding B, Neville BG (2000) Acute disseminated encephalomyelitis, multiphasic disseminated encephalomyelitis and multiple sclerosis in children. Brain 123(Pt 12):2407-2422

43. Berzero G, Cortese A, Ravaglia S, Marchioni E (2016) Diagnosis and therapy of acute disseminated encephalomyelitis and its variants. Expert Rev Neurother 16:83-101

44. ZhR I, Boldyreva MN, Dekonenko EP, Malishev NA, Leontyeva IY, Martinenko IN, Petrukhin AS (2003) Acute disseminated encephalomyelitis in children: clinical features and HLA-DR linkage. Eur J Neurol 10:537-546

45. Massa S, Fracchiolla A, Neglia C, Argentiero A, Esposito S (2021) Update on acute disseminated encephalomyelitis in children and adolescents. Children (Basel) 8:280

46. Varadan B, Shankar A, Rajakumar A, Subramanian S, Sathya AC, Hakeem AR, Kalyanasundaram S (2021) Acute hemorrhagic leukoencephalitis in a COVID-19 patient-a case report with literature review. Neuroradiology 63:653-661

47. de Miranda Henriques-Souza AM, de Melo A, de Aguiar Coelho Silva Madeiro B, Freitas LF, Sampaio Rocha-Filho PA, Gonçalves FG (2021) Acute disseminated encephalomyelitis in a COVID-19 pediatric patient. Neuroradiology 63:141-145

48. Langley L, Zeicu C, Whitton L, Pauls M (2020) Acute disseminated encephalomyelitis (ADEM) associated with COVID-19. BMJ Case Rep 13:e239597

49. McLendon LA, Rao CK, Da Hora CC, Islamovic F, Galan FN (2021) Post-COVID-19 acute disseminated encephalomyelitis in a 17-month-old. Pediatrics 147:e2020049678 
50. Brun G, Hak JF, Coze S, Kaphan E, Carvelli J, Girard N, Stellmann JP (2020) COVID-19-White matter and globus pallidum lesions: demyelination or small-vessel vasculitis. Neurol Neuroimmunol Neuroinflamm 7:e777

51. Haqiqi A, Samuels TL, Lamb FJ, Moharrum T, Myers AE (2021) Acute haemorrhagic leukoencephalitis (Hurst disease) in severe COVID-19 infection. Brain Behav Immun Health 12:100208

52. Chalil A, Baker CS, Johnston RB, Just C, Debicki DB, Mayich MS, Bosma KJ, Steven DA (2021) Acute hemorrhagic encephalitis related to COVID-19. Neurol Clin Pract 11:e147-147e151

53. Karapanayiotides T, Geka E, Prassopoulos P, Koutroulou I, Kollaras P, Kiourtzieva E, Pourzitaki C, Veroniki F, Sintila SA, Astreinidis A, Tsivgoulis G, Grigoriadis N (2020) Concentric demyelination pattern in COVID-19-associated acute haemorrhagic leukoencephalitis: a lurking catastrophe. Brain 143:e100

54. Handa R, Nanda S, Prasad A, Anand R, Zutshi D, Dass SK, Bedi PK, Pahuja A, Shah PK, Sharma B (2020) Covid-19-associated acute haemorrhagic leukoencephalomyelitis. Neurol Sci 41:3023-3026

55. Fitouchi S, Heger B, Kremer L, Kremer S, Ohlmann P (2020) A case of acute disseminate encephalomyelitis after SARS-CoV-2 related acute respiratory distress syndrome. J Neuroradiol. https:// doi.org/10.1016/j.neurad.2020.11.001

56. McCuddy M, Kelkar P, Zhao Y, Wicklund D (2020) Acute demyelinating encephalomyelitis (ADEM) in COVID-19 infection: a case series. Neurol India 68:1192-1195
57. Siracusa L, Cascio A, Giordano S, Medaglia AA, Restivo GA, Pirrone I, Saia GF, Collura F, Colomba C (2021) Neurological complications in pediatric patients with SARS-CoV-2 infection: a systematic review of the literature. Ital J Pediatr 47:123

58. Kelley B, Mixis B, Beinlich B, Chagharvand S, Allen S (2021) Tumefactive acute disseminated encephalomyelitis after recent COVID-19 infection: a case report. Neurology 96(15 Supplement):2121

59. Naik S, Bokka SK, Tareen TK, Naik S, Sagi V, Remmel K (2021) COVID-19 associated acute disseminated encephalomyelitis in adult. Neurology 96(15 Supplement):5002

60. Gonzalez N, Lorenzo J, Wang C (2021) Refractory acute disseminated encephalomyelitis-like findings in a pediatric patient in the setting of SARS-CoV-2 with histopathology. Neurology 96(15 Supplement): 4942

61. Sahlas DJ, Miller SP, Guerin M, Veilleux M, Francis G (2000) Treatment of acute disseminated encephalomyelitis with intravenous immunoglobulin. Neurology 54:1370-1372

62. Keegan M, Pineda AA, McClelland RL, Darby CH, Rodriguez M, Weinshenker BG (2002) Plasma exchange for severe attacks of CNS demyelination: predictors of response. Neurology 58:143-146

63. Ketelslegers IA, Visser IE, Neuteboom RF, Boon M, CatsmanBerrevoets CE, Hintzen RQ (2011) Disease course and outcome of acute disseminated encephalomyelitis is more severe in adults than in children. Mult Scler 17:441-448 